\title{
The effect of instruction on a bi-polar scale
}

M. E. TRESSELT

NEW YORK UNIVERSITY

\begin{abstract}
The problem of this study was to test the effect of instruction on a possible bi-polar scale. One-hundred Ss were tested on a group of 66 words, which in previous testing were judged as belonging to the concept "economic" for $40-60 \%$ of the judgments. One group of Ss was given the instruction to respond "yes" if the word belonged to the concept economic, while the other group was instructed to respond "no" when the words did not belong to the concept "economic." It was hypothesized that by emphasizing the positive end of the scale, more words might be perceived as belonging than if Ss were set for the negative end of the scale. The results show no significant difference with the two sets.
\end{abstract}

\section{Problem}

There are two problems implicit in this study. One problem involved the use of the instruction to form a "set." The literature is replete, with materials in which instructional sets have been shown to influence responses.

Although they were not specifically interested in instructional set, one criticism that can be raised about the work done by Tresselt \& Mayzner (1964) in their study on reinforcement as affecting the shifting of a conceptual scale, is that the instructions were always in the direction of asking the Ss to indicate which words belonged to the concept "economic." They tested 650 Ss ( $50 \mathrm{Ss}$ in each of 13 different experimental conditions). In Condition 1, for example, words that had been previously judged as belonging to the concept "economic" by $80-100 \%$ of the Ss were mixed with words judged as belonging 40-60\%. In another (Condition 9) the range 40-60 was presented alone. Although it was expected that there would be a slight change in the conditions, since the early scaling had a large range of words, the mədian judged as belonging was $62 \%$, higher than the previous median. In Condition 9 where some change may be expected to be occurring just from the lack of the presence of strongly "economic" words, the number of words judged "economic" rose to $72 \%$. It might well be argued that the reason for this shift upwards was the result of the instructions "which words belong to the concept 'economic'." What would happen if the instructions were in terms of which words do not belong to the concept "economic"?

A further problem implicit in this study concerns itself with the possibility that there is a uni-polar scale present in this judgmental situation. If the words are anchored between 2 absolute extremes of "does not belong" through "might belong" to "does belong" then whether positive or negative directions are given, there should be no difference in the number of words categorized. If, however, as suggested by Tresselt (1965) there is a possibility of 2 separate scales being used, i.e., one scale going from "does belong" to "might belong" under positive instructions and "does not belong" to "might belong" under a negative instruction, then the number of words to which the $\mathrm{S}$ responds might differ.

\section{Procedure}

One-hundred Ss were tested individually on 66 words which had been used in a previous experiment and found to have the characteristics of $40-60 \%$ accepted as belonging to the concept "economic." The stimuli were randomized for each pair of Ss: 50 Ss being asked to indicate the words which did belong and the other 50 asked to indicate which words did not belong.

\section{Results and Discussion}

There was no significant difference in the mean number of words chosen. (Mean yes $=51.72$ or $78 \%$; Mean $_{\text {no }}=50.80$ or $77 \%$ ). A spot check of the individual words under the two different instructions did not indicate any significant variations. The results, then, support the earlier findings for these scaled words as being perceived as belonging (78\% as against the $72 \%$ previously found). The negative instruction produced essentially the same results, i.e., $72 \%$ of the words as belonging.

These results indicate that not only are the judgments relatively stable and apparently independnent of the instructional set, but also it suggests that the Ss were utilizing a complete scale ranging from an absolute "does not belong" to an absolute "does belong."

There are several questions raised by these findings. (a) Why do some scales lend themselves to an extreme to neutral position? (b) Which is stronger, an instructional anchoring point or a mental set instruction? (c)What part does the strength of stimuli utilized play in this phenomenon?

\section{References}

Tresselt, M. E. Uni-polar or bi-polar scales of judgment. Psychon. Sci., 1965, 3, 365-366.

Tresselt, M. E., \& Mayzner, M. S. Shifts in connotative meaning of words as a function of context and reinforcement. J. Psychol., $1964,58,317-327$. 